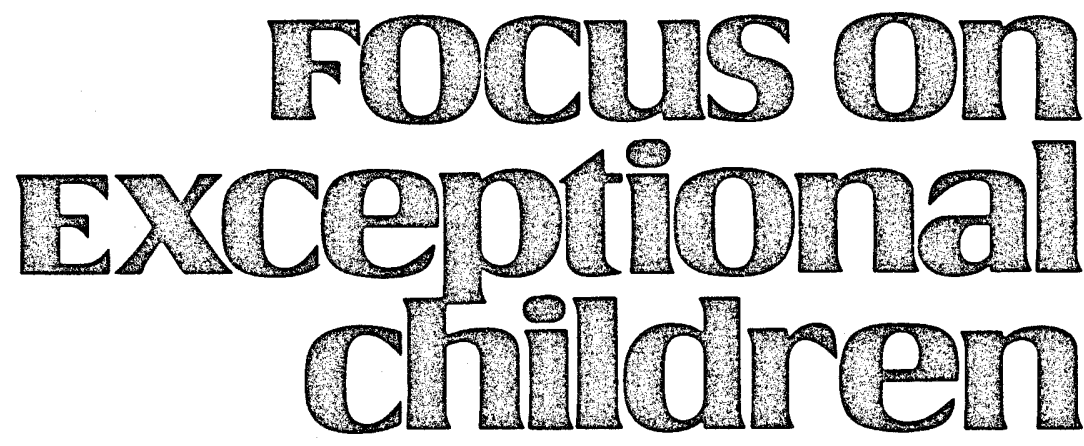

\title{
Linking Assessment, Curriculum, and Instruction Of Oral and Written Language
}

\author{
Caren Wesson, Amy Otis-Wilborn, Jan Hasbrouck, and Gerald Tindal
}

Two major instructional questions addressed by the assessment process, according to Zigmond and Miller (1986), are what to teach and how to teach. In their reconceptualization of the assessment process for instructional planning purposes, they concluded that both questions could be answered best through the use of various informal assessment strategies. They suggested a two-stage process of (a) identifying the broad curricular domain and, (b) selecting specific instructional objectives. Formal testing and functional analysis of environmental demands have been useful in selecting domains in which IEP goals are necessary for the individual exceptional student.

Selection of goals occurs prior to placement in the special education program. Once the student is participating in the special education program, the second stage, informal assessment for selecting identifying objectives, must begin. This process includes:

1. Planning for assessment; selecting or developing a hierarchy of skills or behaviors that represent the domain, deciding at what point in the hierarchy to start the assessment, and selecting or developing a set of tasks to reflect the steps of the hierarchy.

2. Administering the informal assessment survey.

3. Analyzing the students' performance and determining which skills require further probes.

4. Administering more specific probes.

5. Using survey and probe results to specify objectives.

We refer to this process as pre-instructional assessment (PIA).

Zigmond and Miller point to continuous monitoring of student performance as the means for determining how to teach. Documenting the failure of attribute-treatment interaction research, they contend that a priori testing cannot lead teachers to reliably know what teaching methods are best for the individual student. Instead, they suggest "direct and frequent evaluation of student achievement" (p. 507) and reframing of the question "how to teach" to"how can good instruction be responsive to individual differences?" (p. 507). We refer to the assessment conducted to answer this question as on-going monitoring of progress in the domain (OMPD).

Caren Wesson is Associate Professor and Amy Otis-Wilborn is Assistant Professor, Department of Exceptional Education, University of Wisconsin-Milwaukee. Jan Hasbrouck is Instructor and Gerald Tindal is Assistant Professor, Department of Special Education, University of Oregon. 


\section{LINKING ASSESSMENT AND CURRICULUM}

The precedence for PIA and OMPD is found in curriculum-based assessment (CBA) and curriculum-based measurement (CBM). $\mathrm{CBA}$ has become a common term in the special education literature. Differing interpretations and implementations of these terms, however, have caused some misunderstandings. Tucker (1985) defines CBA as using the material to be learned as the basis for assessing the degree to which it has been learned. Complications arise from the various ways in which people define what is to be learned (the curriculum) and how to assess. Because there is no agreement, the combined use of these concepts has led to many vastly different interpretations of CBA (eg., Coulter, 1985; Deno, 1985; Howell \& Morehead, 1987; Marston \& Magnusson, 1985).

In contrast, CBM (Deno, 1985) refers to the repeated use of standard probes that are based on the curriculum. Teachers graph and use the data from these probes to make decisions about the effectiveness of their instruction. Most CBA strategies do not necessarily involve time series analysis for using the data. Thus, CBM becomes a subset of CBA. Because the terminology is confusing and CBA is

\section{Focus on
Exceptional children}

ISSN 0015-511X FOCUS ON EXCEPTIONAL CHILDREN (USPS 203-360) is published monthly except June, July, and August as a service to teachers, special educators, curriculum specialists, administrators, and those concerned with the special education of exceptional children. This publication is annotated and indexed by the ERIC Clearinghouse on Handicapped and Gifted Children for publication in the monthly Current Index to Journals in Education (CIJE) and the quarterly index, Exceptional Children Education Resources (ECER). It is also available in microfilm from Xerox University Microfilms, Ann Arbor, MI. Subscription rates: Individual, $\$ 27$ per year; institutions, $\$ 36$ per year. Copyright (C) 1989, Love Publishing Company. All rights reserved. Reproduction in whole or part without written permission is prohibited. Printed in the United States of America. Second class postage is paid at Denver, Colorado. POSTMASTER: Send address changes to:

$$
\begin{gathered}
\text { Love Publishing Company } \\
\text { Executive and Editorial Office } \\
1777 \text { South Bellaire Street } \\
\text { Denver, Colorado } 80222 \\
\text { Telephone (303) } 757-2579
\end{gathered}
$$

Edward L. Meyen University of Kansas
Glen A Vergason Georgia State University

Richard J. Whelan University of Kansas Medical Center

Stanley F. Love Publisher
Carolyn Acheson Senior Editor open to interpretation, we will use new vocabulary, PIA and OMPD, to clarify the two assessment questions to be addressed here. The questions are:

1. How does a teacher decide for an individual student what should be taught within the domain of oral and written language?

2. How does the teacher know if the instruction in oral and written language is effective for individual students?

To address the first question, special education teachers typically proceed through a series of informal assessment tasks that relate to a hierarchy of skills within the domain of interest. This PIA process, recommended here, will be discussed later.

Most teachers do not directly ask the second question on a regular basis but, rather, assess annually using a standardized test to determine the amount of progress in a general domain. With the research in CBM, educators have become more attuned to the idea of questioning the effectiveness of their instructional approaches. Teachers understand the rationale for this type of assessment because they realize that no direct relationship exists between the mastery of subskills and progress in the whole domain. A student may be able to master the skills of asking questions beginning with the words when, where, how, what, and why, for example, but not be able to use question forms in functional communication contexts.

This relationship between subskills and progress in the whole domain is illustrated best with an example from spelling. All teachers have seen the student who consistently masters the weekly spelling test at $90 \%$, yet fails to improve spelling in spontaneous written expression. Adding up the parts does not necessarily equal the whole.

\section{LANGUAGE, THE CURRICULUM, AND INSTRUCTION}

To clarify the relationship between language curricula and language instruction requires defining the language curriculum and aspects of language performance that signal change and improvement in language proficiency. Oral and written language provide observable means for examining proficiency.

Difficulties with language use, expressively and receptively, cause many students with handicaps to fail in school. Language competence (understanding) and performance (use) are based on a student's proficiency in English language syntax, semantics, and pragmatics, and are the basis for development of most school-related knowledge and skills. In addition, students often are asked to demonstrate their mastery of the school curriculum through oral and written expression. 
The close relationship between oral language and written language is parasitic. Oral language is a reflection of general language comprehension, cognition, and concept development, and written language is built upon general language knowledge and oral language expression (Bereiter \& Scardamalia, 1982). For this reason, examination of a student's proficiency in written and spoken language can help a teacher understand not only a student's general language knowledge but also the student's ability to use language in meaningful ways. The assessment procedures presented here, therefore, focus on writing and speaking and suggest that assessment in these two areas be used in language. Direct parallels between assessing oral and written language will be made.

Language typically is described in reference to four parameters-phonology, syntax, semantics, and pragmatics. Phonology refers to articulation, the phonetic and phonologic components in speech. It is not discussed here because the speech and language pathologist typically assesses and works on speech articulation. Also, handwriting and the use of conventions such as punctuation, capitalization, and spelling are not addressed. These skills are related to written expression as articulation is to oral expression. Although one cannot deny the relationship of phonology and the mechanics of writing to language, a more extensive discussion would be required. Thus, this article focuses on syntax, semantics, and pragmatics.

The development and use of language are complex phenomena, making the process of language instruction complicated. Identification of discrete language behaviors or skills that guarantee an impact on overall language proficiency is difficult. Concern with meeting specific objectives can overshadow the need to look at the effects of language instruction on the broad domain of language. Meaningful assessment of language instruction requires a teacher to take a broad look at language (OMPD) in addition to a narrow one (PIA). The following general process is suggested for designing, implementing, and assessing language instruction.

1. Identify discrete language errors, omissions, or delays demonstrated by the child.

2. Develop instructional plans for working on the discrete language errors.

3. Assess general language functioning. Answer the question: Is overall language improving? If not, are the discrete skills selected for instruction appropriate? Or are the choices of instructional strategies inappropriate or ineffective?

4. Revise/make adjustments in the choice of discrete skills targeted for instruction or revise the instructional plan.
Throughout the process described above, attention also should be given to the student's cultural and linguistic environment. Differences in language patterns, for example, may be attributable to the influence of different cultures, languages, or dialects. This includes the influence of linguistic characteristics of Black English dialect and structure and phonology of foreign languages (GoldenFletcher, 1986).

\section{DEFINING THE CURRICULUM FOR ORAL AND WRITTEN LANGUAGE}

The student's individual needs and cultural and environmental backgrounds as well as expectations regarding language performance in the school setting are factors influencing curricular content and language instruction. Relevant language curricula in oral and written language should be used to guide the pre-instructional assessment process.

Language objectives can be drawn from two sources:

1. Specific aspects that describe the nature and structure of language and communication within the normal language development process.

2. Content inherent in the academic and social environments.

\section{Aspects of Normal Language}

In lieu of an "official" or formal curriculum, the model most often used in assessing language skills is the normal language development sequence. This language development sequence, which grows in content and complexity, also is an appropriate model for examining written language and identifying language delays or omissions. Research on the language development of children with various handicapping conditions has demonstrated that these children often follow patterns of development similar to those of nonhandicapped children (Johnston \& Schery, 1976; Morehead \& Ingram, 1973). Therefore, the normal language model forms the basis for an appropriate language curriculum for children demonstrating language disorders. Language within this model is described in reference to syntactic, semantic, and pragmatic development.

Snytax refers to the grammatical structure and complexity of language (simple, compound, complex sentences), which are developed from the basic parts of speech (noun, verb, adverb, pronoun, etc.) and their functions (subject, predicate, direct object, etc.). Also included in syntax are morphological aspects, the smallest meaningful units of language; they include word endings (e.g., indicating plurality, tense, comparatives, prefixes, 
suffixes, articles, prepositions, and other function words (connecting parts of a sentence).

Semantics refers to the meaning of language at the levels of the lexicon (word) and the sentence. At the lexical levels, semantics involves word meaning or vocabulary. Knowledge and use of vocabulary is quite complex because it is related to a student's overall concept development. Its critical role in language learning recently has been reemphasized (Rice, 1989). At the sentence level, meaning is expressed through relationships built in word combinations (Bloom \& Lahey, 1978).

Finally, pragmatics refers to ways in which language is used. Systems for classifying linguistic functions have been developed to describe the purpose or intent of communication and indicate the effectiveness with which speakers use their knowledge about the communication situation, the participants, and language to achieve the intent.

Pragmatics in written language refers to the functional use of writing. To paraphrase Graves (1983), writing helps us to transcend ourselves in space and time. Writing helps to leave a lasting impression, a remembrance of our thoughts and feelings. Writing is intended to communicate not only to others but also to ourselves. For written language to be understood, it must comply with many of the same standards required of oral language. Contextspecific written language must be used, and it must be approximately correct and complete with respect to semantics, syntax, and the intent or purpose of the communication.

\section{Academic and Social Curricula}

\section{Oral Language Curricula}

Language objectives also can be identified by examining the various "curricula" within the environment. Because most children enter school already having acquired complex oral language communication skills, there is no oral language curriculum per se. For the most part, children are working on developing complexity and proficiency in oral language and communication.

Standard adult English, another model of language, is useful in identifying language differences. A child's language resembles adult language and continues to develop in syntactic and semantic complexity throughout childhood. Also, observing the language/communication models of peers provides useful information regarding appropriate language patterns for a specific age group. Discrepancies between language patterns in adult and peer language and that of an individual student can facilitate the identification of relevant language objectives.
As discussed earlier, oral language curricula may be determined by the linguistic demands of the school, social, and home environments. Academic language includes skills such as asking and answering questions and discourse skills (identifying a topic, commenting on and maintaining the topic, selecting and organizing relevant information, oral reporting). In addition, specific vocabulary is linked with the academic curriculum. Social communication includes various interactions with peers and adults, requiring cooperative group skills, taking turns, and the use of social conventions such as greetings and salutations. The development and use of syntactic, semantic, and pragmatic communication devices facilitate academic learning and successful social interaction.

\section{Written Language}

Academic written language curricular requirements include many tasks ranging from minute responses to broad-based projects. Students learn to fill in the blank with one word or phrase responses in content and comprehension exercises. Students often are required to write sentences or paragraphs of explanation to show understanding of what they read or heard in class discussions. They also write to express their own novel thoughts and ideas. As they mature, student writers compose stories and themes. Some districts require students to pass a theme-writing test prior to graduation. Other academic written language tasks may include some study skills, such as planning for completion of a project, time management, notetaking, and outlining.

Writing is used also for social interactions. The student must be able to communicate in writing to teachers, family, and peers. Social written language curricula include writing notes, such an invitations, thank-you notes, and postcards. Consumer-related skills include writing letters of intent or complaint. Letter writing for a variety of purposes and audiences is an important skill.

\section{PRE-INSTRUCTIONAL ASSESSMENT}

The procedure for assessing language for the purpose of developing specific objectives is broken down into four steps:

1. Identification/definition of relevant curricula (the pool of potential objectives).

2. Assessment of language performance through language sampling.

3. Development of formal objectives to direct language development.

4. Prioritization and selection of objectives for instruction. 
The purpose of the language assessment process is to collect enough evidence to identify errors in what Bloom and Lahey (1978) have defined as the form (syntax/ morphology), use (pragmatics), and content (concepts and ideas, including semantics) of a student's language performance. The assessment process should be based on observation of language, which allows for the identification of (a) linguistic contexts in which the form, function, or content of language is incorrect, (b) contexts in which a specific form, function, or content is required but omitted, and (c) patterns of language performance in response to the demands of academic and social environments.

A direct method for assessing language is through language sampling and analysis. For oral language samples, the manipulation of materials, settings, and language partners and the observation of a student engaged in natural communication situations provide more relevant information for identifying objectives and planning for language intervention. Although a number of formal instruments are available to guide this process, they are limited regarding the parameters of language upon which they focus. Informal but structured methods for collecting, transcribing, and analyzing language samples are more flexible and can be designed to fit the specific focus of assessment and the student's language skill level. In written language, samples that require students to communicate for a variety of purposes and to various audiences form the basis for identifying language errors and pinpointing the objectives of instruction.

\section{Oral Language Samples for PIA}

General sampling requires setting up a communication situation to elicit a large number of utterances reflecting a variety of syntactic, semantic, and pragmatic aspects of language for analysis. The teacher selects the setting, materials, and communication partners to collect a "representative" sample of a student's language production. The larger the sample, the more representative it is of the student's skills.

When collecting a language sample, several variables should be considered. Although the sample should not be limited to sentence-level productions, the majority of the sample should be made up of word combinations, when possible. Next, the setting and materials should be motivating and should provide many opportunities for the student to respond freely. A free-play situation generally is recommended for young children. Toys that a student can manipulate, such as a play house with people, cars, and furniture, are excellent tools. A fuller language sample is achieved if the teacher follows the student's lead regarding the topics discussed. Also, teachers should monitor their own language used to prompt the student. Questions should be open-ended and require more than a yes/no or one-word response.

The sample must be recorded, through a video or audio tape recorder. The teacher can provide comments throughout the tape that will help to identify the context, activity, or any utterances that may be difficult to understand.

The next step is to transcribe the taped or written records. For each sample, the date, time of day, setting, participants, and materials used to elicit language should be documented. Then, student's utterances should be listed. Utterances illustrating an error or omission in content, form, or function, should include the standard English equivalent, which helps to identify specific syntactic, semantic, and pragmatic concerns. Other items that should be documented include contextual factors that indicate (a) verbal or nonverbal stimulus, (b) activity that preceded, accompanied and/or followed the utterance, (c) other important information regarding the context of communication that help explain the intent of the student's utterances. In assessing the intent of the utterance, the teacher should take a child's perspective, not an adult's, by considering all of the contextual factors in relation to the student.

\section{Written Language Samples for PIA}

For sampling written language, teachers should collect several samples of the students' writing before identifying the objectives. The samples should have varying intents; thus, they might include a creative writing sample, a theme about a topic, and a letter. Eliciting several samples increases the likelihood of students' showing all of their skills.

For each sample, teachers should conduct some prewriting activity to activate the student's knowledge and imagination with respect to the topic. For creative writing, teachers should collect two samples-one fantasy situation (e.g., "Once I was marooned on a tropical island. On the other side of the island there lived a ..." and one realitybased situation (e.g., "My favorite chore around the house is ... because ..."). Before writing, the teacher may lead a discussion on the topic, bring in artifacts to stimulate interest, take the students on a visualization journey, or tell or read a related story. Students should have ample time to complete their stories but should do all the writing in school (rather than homework). About an hour can be used to gain each sample.

\section{Analysis of the Oral and Written Language Sample}

Analysis of the oral sample identifies aspects of the student's language that are present and correct, present but 
incorrect (errors), omitted but demanded by the communication situation (omissions), and omitted because of insufficient opportunity during sampling. Identifying errors or omissions is only the first step. The teacher also must determine the nature of the language error or omission because this will influence the kinds of language goals and objectives developed and the instructional approach taken. Ultimately, teachers have to prioritize the language objectives, taking into consideration their impact on overall language proficiency.

\section{Survey of Sample for Errors and Omissions}

The language sample should be surveyed for specific syntactic devices that are used correctly, incorrectly, or not produced. Table 1 gives examples of the more frequent and useful devices available. Objectives that can be developed on the basis of this analysis might include (a) developing syntactic structures and devices for achieving more complex sentences, and (b) developing the use of specific grammatical devices that the student has omitted or used incorrectly.

The language sample should be surveyed to check for the number and variety of semantic roles used correctly. These are defined in Table 2. The student's use of a variety of roles indicates the range of meaning expressed at the sentence level. Table 2 could serve as a checklist.

Conduct a semantic "field-analysis" (Miller, 1981). The purpose of a field analysis is to examine the appropriate meaning conveyed within a sentence (referential meaning) and between sentences within a linguistic context (relational meaning). As teachers survey the overall language sample, they should pose the following questions:

1. Does the vocabulary used match the student's intent?

2. Do sentences fit together meaningfully?

3. Are sentences connected by linquistic references to aspects of time and space?

The objectives that can be drawn from a semantic analysis might include increasing vocabulary knowledge and use, developing understanding and use of various semantic roles, and using referential and relational devices to create continuity between (a) words within sentences, and (b) sentences within paragraphs or discourse.

In analyzing pragmatic aspects of the student's language, the teacher is determining the variety of purposes or functions for which a student can use language, as well as the efficiency with which the student communicates intents. Using the language sample that has been collected, the teacher can survey the sample to identify the presence or absence of pragmatic elements. The pragmatic elements in

\section{TABLE 1}

\section{Syntactic, Semantic, and Pragmatic Language Skills}

Syntax/Morphology
noun phrase/verb phrase
regular plurals
subject pronouns
object pronouns
prepositional phrases
adjectives
interrogative reversals
negatives
verb "be" auxiliary
verb "be" copula
infinitives
determiners
conjunction "and"
possessives
noun/verb agreement
comparatives
wh- questions
past tense
future aspects
irregular plurals
forms of "do"
auxiliaries
derivational endings
reflexive pronouns
qualifiers
conjunctions "and," "but," "or"
conjunctions
indirect and direct objects
adverbs
infinitives with subject
participles
gerunds
passive voice
complex verb forms
relative adverb clauses
relative pronoun clauses
complex conjunctions

Semantics/Vocabulary

Vocabulary

functional words

reading material vocabulary

content area vocabulary

idioms/figurative language

multiple meanings of words

influence of context on meaning

Pragmatics

One-way communication

(oral and written)

expresses wants

expresses opinions

expresses feelings

expresses values

follows directions

asks questions

narrates event

states main idea

sequences events

subordinates details

summarizes

describes

compares and contrasts

gives instructions

explains

\section{Two-way communication} (oral communication)

considers the listener formulates messages participates in discussions uses persuasion resolves differences identifies speaker's

biases

assumptions

formulates conclusions

From K.W. Howell \& J.S. Kaplan, 1980, Diagnosing Basic Skills: A Handbook for Deciding What to Teach (Columbus, $\mathrm{OH}$ : Merrill).

TABLE 2

Semantic Skills: Definitions of 21 Semantic Roles

Action: A perceivable movement or activity engaged in by an agent. Entity: (One-term utterances only) Any labeling of the present
person or object regardless of the occurrence or nature or person or object regardless of
action being pertormed on or by it.

Entity: (Mutti-term utterances only) The use of an appropriate label someone or something gthat caused or was the stimulus to the internal state specified by a state verb or any object or person
that was caused or was the stimulus to the internali state that was caused or was the stimulus to the internal state
specified by a state verb or any object or person that was
modified by a possessive form. (Entity was used to code a modified by a possessive form. (Entity was used
possession if tit met either of the preceding criteria).

Locative: The place where an object or action was located or
toward which it moved. toward which it moved.

Nogation: The impression of any of the following meanings with
regard to someone or something, or an action of state: non-
existence rejection, cossation, denial disappearance. Agent: The performer (animate or inanimate) of an action. (Body
pans and vehicles, when used in conjunction with action vorts pants and vehicles,
were coded Agent.

Object: A person or thing (marked by the use of a noun or pronoun)
that received the force of an action. tan action.

monstrative: The use of demonstrative pronouns or adjectives
this, that, these, those, and the words there, right there, here see, when stated tor the purpose of pointing out a particular

Recurrence: A request for of comment on an additional instance or
amount: the resumption of an event; of the reappearance of amount; the resut
person or object.

Attribute: An adjectival description of the size, shape, or quality of an object or person; also, noun adjinncts that modified nouns for
a s similar purpose ( $\theta$.g., gingertread man). From: Rethertord K.. Schw Possossor: A person or thing (marked by the use of a proper noun
op pronounn) that an object was associated with or to which it
belonged, at least temporarly. Adverbial:
Action/Atribute: A moditier or an action indicating tima, manner,
duration, distance, or frequency. (Direction or place of action

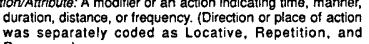
was separately coded as Locative, Repetition, and
Recurrence) Recurrence)
State/Atribute: A moditer indicating time, manner, quality, or intensity of a state. Quantifier: A moditier that indicated amount or number of a person
or object. (Pre-articles and indefinitite pronouns such as a piece
of, lost of, any, every, and each were included.)

State: A passive condition experienced by a person or object. (This
category implies involuntary behavior on the part of the Experiencer, in contrast to voluntary action on the partorto the the
can an Agen: Experiencer: Someone or something that undenwent a given experience of mental state. (Body parts, when used in
conjunction with state verbs, were coded Experiencer.) Recipient: One who received or was named as the recipient of an Beneficiery: One who benefited from or was named as the
beneficiary of a specified action.

Name: The labeling or request for naming of a person or thing
using the utterance torms: my (his, your, etc.) name is using the vtterance torms: my (his. your, etc.) name is
or what's name? Created Object: Something created by a specific activity-lor example, Comitative: One who eccomperied or paticipated with an agent in carrying out a spectified activity.

Instrument: Something that an Agent used to carry out or complete
a specified action. 
Table 1 may serve as a checklist. Elements that were required based on the context but not demonstrated should be noted. The appropriateness and effectiveness of pragmatic functions that were demonstrated should be determined.

In addition, points in the language sample where communication was not successful should be identified. The teacher should try to establish the reason for the breakdown in communication. Was it because the student did not understand the linguistic demands? Did the student have difficulty organizing ideas or sequencing activities? Objectives in the area of pragmatics can be developed that work toward recognition of the need for and the use of a variety of functions of language and development of communication strategies to facilitate successful communication.

\section{Determining Nature and Consistency of Errors}

Answering a series of questions assists in determining the nature of omissions and errors. If the correct linguistic form, function, or content is omitted but demanded, does this reflect (a) an overall delay in language development? (b) a gap in language development? (c) influences of cultural or linguistic differences resulting from the student's home environment? Also, if the child produces the linguistic form incorrectly, does this reflect (a) a deviant or novel form (e.g., "He goed to school")? or (b) cultural or linguistic influences? In addition, for errors, particularly, what linguistic strategies does the student appear to be using? "“Goed" indicates that the student may be using the rule for constructing past tense with regular verb forms that are regular: adding $d$ or $e d$ ). Specific probes should be conducted to support hypotheses.

Also during analysis, the teacher should determine the consistency with which the student produces errors and omission. A search through all available language samples and completion of specific language probes can determine if the child demonstrates errors consistently or inconsistently with some contexts eliciting correct usage. Usually, language forms that are correctly produced in some contexts are easier to teach than those that are never produced correctly.

Finally, for all errors and omission, the teacher should determine if they can be elicited, and at what level. Can the student produce a correct form with a model? Is a prompt required or is it spontaneously used in some contexts? With information regarding the nature of the error or omission, the consistency of its production, and its potential for elicitation, development of objectives and instructional strategies is more closely aligned with individual needs.

\section{ADDITIONAL PIA TECHNIQUES}

\section{Anecdotal Recording}

Anecdotal recording of oral and written language is useful in filling in some of the holes left when using general sampling procedures. General techniques often do not provide opportunities for the child to use particular syntactic forms or language functions. For this reason, monitoring communication throughout the day can provide this information. Particularly important is to document the stimulus context, the student's utterance or writing, and other contextual factors that help to establish the student's intent.

\section{Specific Language Probes}

Probing the oral production of specific language forms, content, and functions, can be done after a preliminary analysis. At this level, the teacher creates communication situations that prompt-for example, the use of a specific syntactic structure that should be in the student's repertoire or a language function demanded in the academic or learning context. Specific language probes can be developed to target syntactic, semantic, and pragmatic domains of language performance. For example, in oral language, to probe for the use of past tense, questioning or picture cues might be used to elicit what happened immediately following a recently completed activity. In probing the use of requests, the teacher might set up a motivating activity in which the student must ask for materials in order to complete the task. The responses should be recorded.

Following analysis of the general written language sample, teachers should prompt students to edit and make corrections (e.g., "Try to fix your wording by adding more descriptive words"). The edited versions should be analyzed so the teacher can decide which skills should be taught at the acquisition level and which have to be shaped to become automatic and fluent. Further specific probes to elicit untapped skills may be conducted. For example, if the student uses a limited vocabulary, the teacher may devise a synonym activity in which the student writes all the words he or she can think of that relate to words such as "cold" or "pretty." The teacher then can evaluate semantic skills.

\section{MONITORING PROGRESS IN ORAL AND WRITTEN LANGUAGE DOMAINS}

Assessment activities at this level require demonstration of the integration of a variety of discrete language skills. Assessment tasks also may combine reading, writing, and oral language with relevant academic and social content, 
which, again, emphasize or capitalize on the parasitic nature of language. Potential assessment strategies for OMPD in language are described next.

\section{Collecting Brief Oral and Written Samples}

The teacher might collect an oral or written language sample using a picture stimuli along with the directions, "Tell me a story about what you think is happening in the picture" or "Describe what you see in this picture." As examples, the picture may be of an Indian girl looking down at a herd of horses, a boy looking up at the shapes in the clouds, a girl throwing a penny into a fountain, a dog sleeping under a porch, or two boys carrying fishing poles. Again, care should be given to the child's experiential background as related to the pictures. Teachers should use pictures that depict familiar scenes or story starters to elicit oral and written language. The length of time required for collecting this sample may be as short as 1 minute. Teachers should collect writing samples following a standardized process. Initially, two or three samples should be collected over a period of a few days.

A structured method for collecting a brief written language sample follows. Although students actually write for only 3 minutes, 10 minutes of class time should be allowed for each sample collected-for giving directions, answering questions, writing, and passing in papers. A stopwatch or a watch with a second hand is required, and each student will need a blank sheet of lined paper and a pencil. They then complete their stories, within a reasonable amount of time. Directions to students are:

I want you to write a story. I will read the beginning of a story to you first. Then I want you to write a story about what happens next. You will have 30 seconds to plan what you will write. Use that time to decide what will happen in your story. You will have 3 minutes to write. At the end of 3 minutes, I will say "time" and you will mark a star on your paper after the last word you wrote. (Demonstrate on board.) If you like, you will then be able to finish your story and give it a title. Start your story with your own words. You should not write the words that I read to you. You won't write a title for this story until you are finished. Are there any questions? ... . Listen carefully. For the next 30 seconds I want you to think about a story that starts like this: (Example) "I went up to the old, deserted house. The door was open, so I walked in. Suddenly ..."

During the time the students are writing, no questions can be answered regarding spelling or story ideas. The story starter may be repeated if necessary. Students should be encouraged to write for the entire time.

A similar procedure may be used in sampling oral language, using the story starter and giving students time (30 seconds) to think. Then they have 1 to 3 minutes (being consistent across samples) to complete the story orally. The teacher tapes, writes, or types the student's responses.

\section{Analysis of Brief Samples}

\section{Syntax}

The purpose of the following analysis procedure is to provide measures of syntactic complexity and use of specific syntactic devices. Mean length of utterance (MLU) and measures of sentence complexity are offered as suggestions.

Mean Length of Utterance (MLU). As a child begins to combine propositions, the sentence length grows. This measure is an indicator of syntactical complexity for children who are producing up to five MLUs. The MLU can be used to identify if the student is producing sentence lengths appropriate for his or her age (see Miller, 1981, for specific instructions). Also, MLU is associated with the development and use of specific grammatical morphemes. Brown (1973) has identified three stages associated with levels of MLU during which specific morphemes appear. In written language, T-unit length-the shortest complete, nonfragmented, segment of a passage-is used to assess syntax (Isaacson, 1988). T-unit length in written language is comparable to MLU in oral language.

Sentence Complexity. The number of simple, compound, and complex sentences the student produced in the sample is counted, and percentage of the total sample that each sentence type represents is computed. As language develops, students begin to use syntactic devices to combine sentences. For example:

Simple sentence level-The boy went to school. The girl went to school.

Compound sentence level-The boy and the girl went to school.

Complex sentence level-The boy and the girl who were good friends went to school first and then to the playground.

\section{Semantics}

Analysis of semantic aspects of a child's language provides information regarding vocabulary knowledge and use. The following procedure may help to monitor semantic development. 
Type Token Ratio. The type token ratio (TTR) for language samples is computed. The TTR is a measure of the use of different words. Most children with normally developing oral language have a ratio of .50 (Templin, 1957). If the ratio is less than .50 , the student is using a smaller range of vocabulary; if the ratio is more than .50 , he or she is using a wide range of vocabulary. Although this measure is most frequently used to assess oral language, it can also be used to evaluate writing (Isaacson, 1988).

Vocabulary Use. Because a word is used in spontaneous oral or written language, it is assumed that the student has a basic conceptual knowledge of the word's meaning in the context in which it is used. Vocabulary knowledge, however, involves more. The knowledge and manipulation of known vocabulary can be evaluated by randomly selecting a few of the content words in the student's oral or written language sample and asking the student to: (a) use the words in another sentence, (b) give antonyms or synonyms for the words, and (c) provide examples or definitions for the words. These tasks can require oral or written responses. A record of the percent of correct responses should be graphed.

\section{Integrated Measures}

Integrated measures reflect a student's ability to integrate aspects of syntax and semantics. These measures include number of words produced, number of correct word sequences, and mean length of word sequences.

Total Words Produced. The first integrated measure involves collecting a one minute sample in oral language and a three minute sample in written language based on a story starter. The scoring procedure is to count the total words used in the sample (Deno, Marston, \& Mirkin, 1982). This measure of written or oral fluency is best used until the students are writing or talking fairly fluently, at which point a different measure would be more helpful as the objective switches from saying or writing more words to saying or writing in a more meaningful way.

Number of Correct Word Sequences. This is used to calculate the mean length of correct word sequences. A correct word sequence is defined as a sequence of two adjacent correctly spelled words that is acceptable within the context of the larger phrase/sentence to a native speaker of the English language. The term "acceptable" means that the scorer judges the word sequence as syntactically and semantically correct and appropriate (Videen, Deno, \& Marston, 1982). A caret mark $(\wedge)$ placed above and between the two words is used to indicate each correct word sequence. An unbroken sequence of carets may continue as far as the end of the sentence. Sequences stop at the end of sentences, before an incorrect conjunction, or whenever two adjacent words are not both syntactically and semantically correct (Parker \& Tindal, 1988). If a conjunction is used improperly to link three or more clauses, the scorer must judge which pair of clauses fit best together, if any. The incorrect conjunction will be an error, with correct sequences ending at the extraneous conjunction.

Mean Length of Correct Word Sequences. A widely accepted objective for written language is for students to use expanded sentences to increase syntactic maturity (Isaacson, 1988). To score this aspect of students' writing, or oral language, parentheses are placed around each unbroken string of adjacent carets marking correct word sequences. The number of carets marking unbroken sequences within each set of parentheses are counted, and those numbers are summed. The sum is divided by the total number of sets for the mean length of correct word sequences (Hasbrouck, 1988). An example is:

$$
(\wedge \wedge \wedge) \quad(\wedge \wedge)
$$

I seen a great huge monster and it was green

$$
(\wedge \wedge \wedge \wedge) \quad(\wedge)
$$

and it started to attack me and then I seen

$$
(\wedge \wedge \wedge \wedge \wedge \wedge \wedge \wedge \wedge \wedge
$$

something that I could pick up to get the mon-

$\wedge)$

$(\wedge)$

$(\wedge \wedge \wedge \wedge$

ster away so bent down and $I$ got it but it

$\hat{\text { seemed to .... }}$

Correct Word Sequences $=26$

Mean Length of Correct Word Sequences $=$ $26 / 7=3.7$

\section{Pragmatics}

When pragmatics is the emphasis, two possible suggestions for OMPD are given. Both of these suggestions are speculative, as there is no research in ongoing monitoring of pragmatic development. These scales may be used after the student has had time to generate an entire story in oral or written form.

1. Isaacson (1988) offers four aspects of content that could be rated using a holistic or analytic scale: idea generation, coherence, organization, and awareness of audience. Though these elements are designed for analysis of written language, they may also be applicable to oral language. A 4-point scale for each of the four items provides a 16-point range in which to chart progress. Figure 1 depicts this scale. 


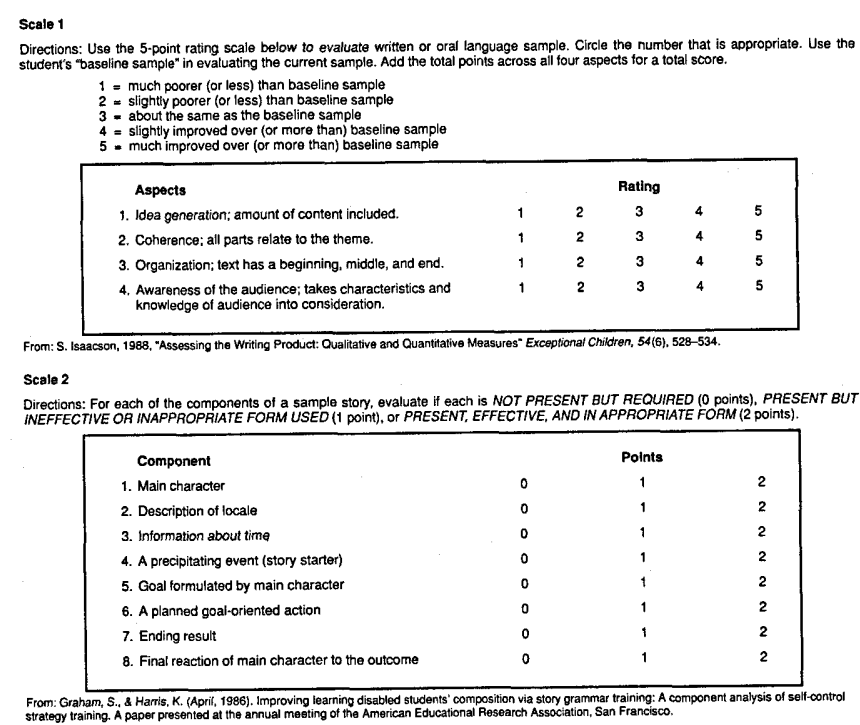

Figure 1

Pragmatic Rating Scales for Four Written and Oral Aspects of Language Sample

2. Graham and Harris (1986), as discussed by Isaacson (1988), list eight story elements that could be used as items on a rating scale if a story starter is used to elicit the sample. The elements of the story are main character, locale, time, precipitating event, a goal formulated by the main character, a planned action to achieve the goal, an ending, and a final reaction, as presented in Figure 1. Graham and Harris use scores indicating each element's inclusion and quality of development. A $0-, 1-$, or 2- point scale is suggested here.

\section{USING THE OMPD DATA}

All of the OMPD data in oral and written language can be charted on a graph, and these graphic presentations of students' performances can be used to make decisions about the overall effectiveness of instruction. There are many choices of procedures to use for analyzing the data. The main step for using the data are:

1. Decide on the OMPD domain to be used for each individual student, and prepare probes for each level.

2. Set up a measurement station containing all measurement stimuli, graphs, pencils, stopwatches, and a system for organizing the graphs.

3. Label graphs completely for all students.

4. Take baseline data for all students.

5. Given baseline data recorded on the graph, choose the strategy for making expectations for each student.

a. Alternate interventions as in an applied behavior analysis single-case study research design, to determine which intervention is the most effective for each student. The graph would show baseline, followed by at least 6 data points in treatment A, 6 or more data points in treatment $\mathrm{B}, \mathrm{A}, \mathrm{B}, \mathrm{C}$, etc. Systematically vary the intervention (treatment) to ascertain which is most effective for the individual student.

b. Set a line of expected progress and make decisions about the effectiveness of instruction based on how closely the student's performance data match the aimline (line of expected progress drawn on the graph). Some teachers do this on an annual basis when using a OMPD system. The key to using the data in this manner is setting a reasonable goal. Teachers have to be careful to not set goals too low. Some teachers use the performance of mainstream students to set the goals for the special needs students. The teacher may consider, for example, that Joe will be mainstreamed into a fourth grade class for writing next year and may decide to find out what the average performance in writing is in the current year's fourth grade class. The assumption is that if Joe can catch up to that level, he will be ready in fall to attend that written language mainstream class. Other teachers pick a rate of progress they would like to see the individual student attain and set the goal according to that rate. For example, the teacher may expect Sally's oral expression skills to improve by one additional word per story she tells per week. So, if Sally tells an average of 22 words in her stories in the fall, the goal would be set at $(22+36$ [number of weeks in the school year $x$ one word per week improvement] $=58$ ) 58. The intersection of the last week in school along the horizontal axis and the rate of 58 along the vertical axis is the place to mark the $\mathrm{X}$, which represents the annual goal. Connecting the median score of a 3-5 day baseline period to the $x$ representing the goal provides teachers with the aimline.

6. After the graphs are set up, delineate the instructional plan, specifying objectives, instructional strategies, motivational techniques, materials, time allotted per activity, and arrangements for the activities (independent, one-to-one with teacher, small group). Only by routine implementation of specific strategies can teachers use the data. This concept is analogous to the idea of treatment in applied behavior analysis. The data for treatment A must all mean the same thing; the student was exposed to the same regimen consistently.

7. After deciding on a strategy for using the data (5a or $5 b$ ), collect data twice a week. Data points are charted routinely; many teachers have the students chart their 
own data. On a weekly basis the teachers pause and reflect on the graphed data, deciding either that the intervention in place is effective and should remain or that a change in instruction is necessary.

8. Add a new strategy or replace a strategy. Whatever the change, it should be substantial and have the potential for making a difference in the student's performance. Slight alterations will have little effect on the student's performance and should be avoided.

After the system is in place, the routine is to collect data, evaluate the effects of instruction using the data, change the instructional plan as necessary, and continue collecting data.

\section{ISSUES TO CONSIDER}

Because of the nature and complexity of language, any of the tasks that have been recommended must be considered in light of other contextual factors that may be related to performance. For example, when antonyms and synonyms seem to be a problematic skill, teachers also must consider the student's (a) experience and knowledge of word concepts, (b) cognitive understanding of antonyms or synonyms, (c) efficient retrieval of words, and (d) understanding of the context in which this skill is being assessed (written or oral test, discussion, etc.). Further, in written language, the teacher must consider the complexity of the task demands, the student's organizational abilities, visual motor skills for producing legible written products, skills in retrieval of words and sentences, skills in transferring thoughts to paper, and spelling demands.

If these measures are to be useful in determining the effectiveness of instruction, there is the need to develop techniques that meet the criteria of validity, reliability, and sensitivity. Research in similar measures in other academic areas has been successful in identifying measures that meet these criteria (Deno, 1985). The issue of sensitivity to change is most critical, and is especially so in language as language growth may be slow and diverse. Therefore, it is often difficult to document improvement.

Because language is so pervasive and critical to success in academic and social life, ways in which to develop, refine, and improve proficiency in language requires attention. The complexity of language, however, makes it difficult to monitor. Hence, the need for measures that can direct instruction in ways more efficient than "current practice" is great. Current practice includes the use of trial and error in instruction; instruction in language that is splintered from the rest of the curriculum; and language instruction that is random and inconsistent.

Efficiency of OMPD strategies is another issue that must be addressed. Teachers should spend most of their instructional time teaching rather than testing. Therefore, the system for OMPD has to be efficient. Ideas about how to decrease measurement time include having the students themselves prepare materials (select probes), setting up a measurement station, having assistants administer the measures, and having the students do self-charting (Wesson, 1987).

The progress monitoring measurement is done twice a week with students whose progress rate is less than expected. More frequently collected data allow for more effective instructional planning. For students who are making progress in the domain at an acceptable or expected rate, the frequency of measurement may be once a week or biweekly.

In the future, computerized language assessments will be available whereby teachers can type into the keyboard as the student dictates the story or gives the directions. For written language, students will type in their own stories. The software will score, chart, and print the graph. Various scoring options will be available for both written and oral language.

\section{CONCLUSION AND SUMMARY}

Assessment procedures that help educators make decisions about what to teach and about the effectiveness of their choices of teaching strategies are crucial. Traditional formal tests do little in this regard; they serve primarily as evidence for the necessity of special services (Deno, 1985). Educators express the need for assessment data that can be meaningfully used in formulating and evaluating educational interventions. In special education, where the legal mandate is for individualized instruction, this need is even greater. Special educators must systematically plan for and evaluate the effectiveness of the strategies they use with each student.

Teachers make a multitude of decisions. Effective teachers continuously question what they have done and what they should do with respect to instruction. Within each academic area, two of the most important questions special education teachers make about individual students are: (a) what skills do I need to teach this student? and (b) is my plan for teaching this student effective? The first question leads to the development of goals and objectives and ultimately to the teacher's daily lesson plans. Basically, the teacher assesses the student within a domain, such as reading or math, to determine what the student already knows and what skills the student has mastered. At the same time, the teacher also determines what skills and content should be taught and practiced. But, deciding on what should be taught is only one side of the coin. Special education teachers also must evaluate the effects of their instruction on student performance. 


\section{REFERENCES}

Bereiter, C., and Scardamalia, M. (1982). From conversation to composition: The role of instruction in a developmental process. In I.R. Glasser (Ed.)., Advances in instructional psychology (vol. 2, pp. 1-64). Hillsdale, NJ: Laurence Erlbaum.

Bloom, L., \& Lahey, M. (1978). Language development and language disorders. New York, NY: John Wiley \& Sons.

Brown, R. (1973). A first language. Cambridge, MA: Harvard University Press.

Coulter, A. (1985). Implementing curriculum-based assessment: Considerations for pupil appraisal professionals. Exceptional Children, 52 (3), 277-281.

Deno, S. (1985). Curriculum-based measurement: The emerging alternative. Exceptional Children, 52 (3), 219-231.

Deno, S., Marston, D., \& Mirkin, P. (1982). Valid measurement procedures for continuous evaluation of written expression. Exceptional Children, 48, 368-371.

Golden-Fletcher, D. (1986). Language of bilingual-bicultural children. In V. Reed, An introduction to children with language disorders. New York, NY: Macmillan, pp. 181-200.

Graham, S., \& Harris, K. (April, 1986). Improving learning disabled students' composition via story grammer training: A component analysis of self-control strategy training. A paper presented at the annual meeting of the American Educational Research Association, San Francisco.

Graves, D.H. (1983). Writing: Teachers and children at work. Exeter, NH: Heinemann.

Hasbrouck, J. (1988). Objective and holistic scoring of writing: A manual for collecting and scoring writing samples using holistic and 8 objective scoring procedures (Module No: 20). Eugene, OR: Resource Consultant Training Program, University of Oregon.

Howell, K.W., \& Kaplan, J.S. (1980). Diagnosing basic skills: A handbook for deciding what to teach. Columbus, $\mathrm{OH}$ : Merrill.

Howell, K., \& Morehead, M.K. (1987). Curriculum-based evaluation for special and remedial education. Columbus, $\mathrm{OH}$ : Merrill.
Isaacson, S. (1988). Assessing the writing product: Qualitative and quantitative measures. Exceptional Children, 54(6), 528-534.

Johnston, J., \& Schery, T. (1976). The use of grammatical morphemes by children with communication disorders. In D. Morehead \& A. Morehead (Eds.), Normal and deficient child language. Baltimore: University Park Press.

Marston, D., \& Magnusson, D. (1985). Implementing curriculum-based measurement in special and regular education settings. Exceptional Children, 52(3), 266-276.

Miller, J. (1981). Assessing language production in children: Experimental procedures. Austin, TX: Pro-Ed.

Morehead, D., \& Ingram, D. (1973). The development of base syntax in normal and linguistically deviant children. Journal of Speech \& Hearing Research, 16, 330-352.

Parker, R., \& Tindal, G. (1988). Direct, objective measures of writing skills for middle school students with learning disabilities. Unpublished manuscript, University of Oregon, Eugene.

Retherford, K., Schwartz, B., \& Chapman, R. (1981). Semantic roles and residual grammatical categories in mother and child speech. Journal of Child Language, 81(3) 583-608.

Rice, M. (1989). Synthesis/commentary on language teaching and learning strategies. In M. Rice and R. Schiefelbusch (Eds.), The teachability of language, Baltimore, MD: Brookes Publishing Co.

Templin, M.C. (1957). Certain language skills in children: Their development and interrelationships. Child Welfare Monographs, No. 26. Minneapolis: University of Minnesota Press.

Tucker, J. (1985). Curriculum-based assessment: An introduction. Exceptional Children, 52(3), 199-204.

Videen, J., Deno, S., \& Marston, D. (1982). Correct word sequences: A valid indicator of proficiency in written expression (Research Report No. 84). University of Minnesota: Institute for Research on Learning Disabilities.

Wesson, C. (1987). Increasing efficiency. Teaching Exceptional Children, 20, 46-47.

Zigmond, N., \& Miller, S. (1986). Assessment for instructional planning. Exceptional Children, 52(6), 501-509.

\section{Professional update}

Technology and Media Division
Council for Exceptional Children

January 11-13, 1990

Lexington, Kentucky

Contact: Joel Mittler

School of Education

Long Island University

Brookville, New York 11548

\section{Association for Children and Adults with Learning Disabilities}

February 21-24, 1990

Anaheim Hilton Hotel

Anaheim, California

\section{Council for Exceptional Children}

April 23-27, 1990

Toronto, Ontario, Canada

Contact: CEC

1920 Association Drive

Reston, Virginia 22091

\section{American Association on Mental Retardation}

May 27-31, 1990

Atlanta, Georgia

Contact: AAMD (202) 387-1968 